\title{
Physical exercise during pregnancy and its influence in the type of birth
}

\author{
Exercício físico durante a gestação e sua influência no tipo de parto
}

\author{
Lílian Cristina da Silveira ${ }^{1}$, Conceição Aparecida de Mattos Segre ${ }^{2}$
}

\begin{abstract}
Objective: To verify if medium intensity exercise performed during pregnancy can influence in the type of delivery, and to observe compliance to an exercise program among primiparous women with different levels of schooling. Methods: A study carried out at the Centro de Incentivo ao Aleitamento Materno, in São Sebastiao (SP), between April 7, 2008, and April 14, 2009. A prospective study involving 66 primiparous women who were divided into two groups: an Exercise Group, engaged in regular physical activity during pregnancy, and the Control Group, that did not participate in regular physical activity during the same period. Significance level in this project was $5 \%(p=0.05)$. Results: The group that did engage in regular exercise had a higher rate of vaginal deliveries, with a statistically significance difference evaluated by the $\chi^{2}$ test $(p=0.031)$. The pregnant women with the highest level of schooling showed greater compliance with the exercise program, with a statistically significant difference $(p=0.01736)$. Conclusion: Physical exercise in primiparous women increased the chances of vaginal deliveries, and there was greater compliance with the exercise program among those with a higher level of schooling when compared to those with a basic education.
\end{abstract}

Keywords: Exercise; Pregnant women; Natural delivery; Cesarean section

\section{RESUMO}

Objetivo: Verificar se o exercício físico de média intensidade, realizado durante a gestação, pode influenciar na via de parto, e observar a adesão ao exercício entre primigestas com diferentes níveis de escolaridade. Métodos: Estudo realizado no Centro de Incentivo ao Aleitamento Materno, em São Sebastião (SP), entre 7 de abril de 2008 a 14 de abril de 2009. Estudo prospectivo envolvendo 66 gestantes primíparas, as quais foram alocadas em dois grupos, um Grupo Exercício, que praticou atividade física regular durante a gravidez, e o Grupo Controle, que não praticou atividade física regular durante 0 mesmo período. 0 nível de significância adotado neste trabalho foi de $5 \%(p=0,05)$. Resultados: 0 grupo que praticou exercício regular teve maior número de partos vaginais, com diferença estatística significativa avaliada pelo teste do $\chi^{2}(p=0,031)$. As gestantes com melhor nível de escolaridade apresentaram maior adesão ao programa de exercícios, com diferença estatisticamente significante $(p=0,01736)$. Conclusão: 0 exercício físico em primíparas aumentou as chances de ocorrência de parto vaginal e, ainda, foi observada maior adesão ao exercício entre grávidas com nível superior de escolaridade quando comparadas a grávidas com nível fundamental de escolaridade.

Descritores: Exercício; Gestantes; Parto normal; Cesárea

\section{INTRODUCTION}

Over the last few years, growth in the number of cesarean sections has been observed ${ }^{(1-7)}$. On the other hand, various studies showed that they are associated with a longer hospital stay and an increased risk of infection ${ }^{(1,2,4)}$ for the mother, a greater chance of developing respiratory distress syndrome for the newborn, and greater morbidity and mortality for both mother and child ${ }^{(1-3,5)}$.

Despite the fact that cesarean sections elevate the costs for the public healthcare system, with a greater number of medical visits and longer hospital stays ${ }^{(2,4,5)}$, in Brazil the number of cesarean sections continues to rise. According to the Ministry of Health, the proportion of cesarean sections in Brazil was 52.34\%, in 2010, considering the public and private sectors ${ }^{(6)}$, reaching

\footnotetext{
Study carried out at Centro de Incentivo ao Aleitamento Materno (CIAMA), São Sebastião (SP), Brazil. [ Article based on the Master's degree thesis submitted to the Graduate Course in Health Sciences, from the Instituto de Assistência Médica ao Servidor Público Estadual (IAMSPE) and approved on November 9, 2010.]

${ }^{1}$ Centro de Incentivo ao Aleitamento Materno (CIAMA) - São Sebastião (SP), Brazil; Instituto de Assistência Médica ao Servidor Público Estadual - IAMSPE, São Paulo (SP), Brazil.

${ }^{2}$ Instituto de Assistência Médica ao Servidor Público Estadual - IAMSPE, São Paulo (SP), Brazil.

Corresponding author: Lílian Cristina da Silveira - Avenida Ibirapuera, 981 - Vila Clementino - Zip code: 04029-000 - São Paulo (SP), Brazil - Phone: (55 11) 5088-8000 - E-mail: liliancsilveira@yahoo.com.br Received on: Oct 27, 2011 - Accepted on: June 15, 2012
}

Conflict of interest: none. 
$80 \%$, in 2007 , in the private sector alone ${ }^{(7)}$. These figures are significantly higher than 10 to $15 \%$ recommended by the World Health Organization (WHO) ${ }^{(8)}$. Some studies also showed that the number of cesarean sections increases in the richest regions and is directly related to a higher level of education and to prenatal visits ${ }^{(2)}$.

Several proposals have been made to try to change this scenario, and one of them is the regular participation of pregnant women in physical activities during gestation, which seems to be associated with a smaller rate of cesarean sections in nulliparous women ${ }^{(9-11)}$. The American College of Obstetrics and Gynecology (ACOG) recommends the practice of 30 minutes of daily exercise, of moderate intensity, for pregnant women with no clinical or obstetric complications ${ }^{(12,13)}$.

Besides the possibility of contributing towards a vaginal delivery, physical exercise during gestation seems to afford other advantages, such as a protective effect against premature labor ${ }^{(14)}$, increased index of amniotic fluid and edema reduction in pregnant women ${ }^{(15)}$, and reduced risk of developing gestational diabetes ${ }^{(16)}$. Moderate physical activity during pregnancy can contribute towards smaller weight gain ${ }^{(17)}$, improved functional capacity ${ }^{(18)}$, and lessened low back pain intensity ${ }^{(19)}$. Additionally, exercising the pelvic floor muscles during pregnancy decreases the incidence of urinary incontinence, both during pregnancy and after the delivery ${ }^{(20)}$. It is necessary to point out, however, that high intensity exercises should be avoided during this period ${ }^{(21)}$, since at this level there is an increased risk of spontaneous abortion ${ }^{(14)}$ and premature labor ${ }^{(17)}$, as well as transient fetal bradycardia after intense physical activity ${ }^{(22)}$, restriction of fetal growth $^{(12)}$, and greater chance of low birthweight ${ }^{(13)}$. On the other hand, moderate physical activity seems to be safe for the mother and fetus and can be done, as long as there are no contraindications ${ }^{(10-12,14,18)}$. Considering the growing number of cesarean births and, on the other hand, the possibility of regular physical activity contributing to a greater chance of natural deliveries, besides the safety that regular medium intensity physical exercise affords the mother-child pair, this study was proposed.

\section{OBJECTIVE}

To verify if medium intensity physical exercise performed during gestation can influence in the type of delivery between the group engaged in physical exercise and the group that did not participate in any regular exercise during this period, and to observe the relation between compliance with physical exercise and level of schooling of the pregnant women.

\section{METHODS}

The present study was prospective and was carried out at the Centro de Incentivo ao Aleitamento Materno (CIAMA) [Breastfeeding Promotion Center], in São Sebastião (SP). The period of research went from April 7, 2008, to April 14, 2009.

With the purpose of testing the operability of the study, a pilot study was conducted with five pregnant women between May 14 and July 25, 2007, and these pregnant women were not included in this research.

The participants were recruited during a preparatory breastfeeding program at the place the study was performed, by means of information given during the prenatal visits carried out in the outpatient clinic of the Family Health Program (PSF, acronym in Portuguese) and in a local printed newspaper. All pregnant women were invited to participate in the exercise program. They received verbal information as to how the study would be conducted and, after agreeing to participate, signed the informed consent form.

Initially, 97 nulliparous pregnant women, who were sedentary, aged 18 to 30 years and gestational age $>18$ weeks, with no clinical or obstetric complications or with a single gestation were accepted for participation in the study. Those who opted for not engaging in activity were enrolled in the Control Group (CG) and the ones that accepted participation in physical activity were place in the Exercise Group (EG).

In order to be included in the EG, the women could not be more than $>20$ weeks pregnant and had to participate in regular physical activity, twice a week, with a minimal participation in 20 sessions. The pregnant women with a frequency lower than 20 sessions were eliminated. Those from the CG were not to engage in regular physical activity during pregnancy.

In both groups, the participants had not participated in regular physical activity during the year prior to gestation, including, in this way, only those who were sedentary.

Gestational age was obtained by means of the date of the last menstrual period or ultrasound test for all subjects.

Excluded were the pregnant women who had clinical and/or obstetric complications; those who did not reach the minimal participation in the exercise sessions, and those who lost contact or abandoned the program. Thus, of the 97 pregnant women, 31 were eliminated: 3 due to spontaneous abortion, 2 of them from the $\mathrm{CG}$ and 1 from the EG; one due to anemia from the EG; one due to pre-eclampsia from the CG; 2 due to loss of contact after the delivery - one from each group; 11 from the EG did not reach the minimal 
number of sessions; 7 reported having personal reasons for dropping out - 5 from the $\mathrm{CG}$ and 2 from the EG; 6 participants abandoned the study.

In this way, a total of 66 pregnant women, primiparas and those with low risk participated in the study, and were allocated to one of the two groups: in the EG were those who engaged in regular physical activity twice a week $(n=37)$ and in the CG those who did not do any regular physical activity during gestation $(n=29)$. The sample " $n$ " was similar to samples of previous projects performed ${ }^{(10,15,22)}$.

Physical activity was directed by a physical therapist, who was available to explain any doubts or questions regarding the exercise and the study. ACOG guidelines were followed as to room temperature, which had air conditioning, and the temperature did not exceed $28^{\circ} \mathrm{C}$. The women were instructed to use comfortable clothing and to drink water before and during the activity, and to not exercise while in the fasting state ${ }^{(21)}$. They were also instructed to interrupt activity if they felt dizziness, shortness of breath, pain, muscle weakness, or dyspnea before the exertion, or if they had pain or swelling in their calf, bleeding or signs of labor ${ }^{(12,13)}$, or when they perceived a drop in fetal movement ${ }^{(21)}$.

The participants filled in a screening questionnaire with information on personal data, schooling level, height, weight, type of healthcare (private or public), gestational age, health status, presence of bleeding, and practice of physical exercise during the gestation. Another questionnaire was applied to collect information about participation in regular physical activity over the previous two weeks, and how much time was spent on that. The physical activity was performed as a group; before the activity, a talk was given covering the benefits of a normal delivery compared to a cesarean section, description of physical exercises for pregnant women, and orientation as to postures to be used during labor, such as giving preference to the orthostatic position, walking, and squatting ${ }^{(8,23-27)}$. Those from the CG also participated in at least three talks with orientation as to the postures recommended during labor and as to vaginal deliveries.

\section{Exercise program}

During the first two weeks, the exercise session was begun with 5 minutes of stretching, followed by 30 minutes of strengthening, and at the end, another 5 minutes of stretching. As of the $2^{\text {nd }}$ week, the pregnant women did 40 minutes of strengthening. Each strengthening activity was initiated with 10 repetitions, during the $1^{\text {st }}$ week, and 20 during the $2^{\text {nd }}$ week, reaching
30 repetitions during the $3^{\text {rd }}$ week and maintaining this number until the end of the training. The frequency of classes was twice a week and no additional form of resistance was offered besides the weight of the limb itself. The pregnant women were able to initiate activity as of the $8^{\text {th }}$ gestational week, maintaining their training until the end of gestation, and engaging in at least 20 sessions. The activity was carried out in standing position (orthostatic), sitting, lateral decubitus, position with four points of support, and squatting, as described on chart 1.

Chart 1. Exercise program for specific muscle groups

\begin{tabular}{|c|c|c|}
\hline Posture & Stretching & Strengthening \\
\hline Orthostatic & $\begin{array}{l}\text { Quadriceps, sural triceps } \\
\text { and pectora|(24) }\end{array}$ & $\begin{array}{l}\text { Quadriceps, sural triceps } \\
\text { and hip abductors } \\
\text { (25) }\end{array}$ \\
\hline Sitting & $\begin{array}{l}\text { Hip adductors, hamstring } \\
\text { and sural triceps } \\
\text { (26) }\end{array}$ & \\
\hline Supine position & $\begin{array}{l}\text { Gluteus, paravertebral, } \\
\text { lumbosacral|25-27) }\end{array}$ & $\begin{array}{l}\text { Abdominal| }{ }^{(26)} \text {, hip } \\
\text { extensors and adductors, } \\
\text { pelvic floor }{ }^{(25-27)}\end{array}$ \\
\hline $\begin{array}{l}\text { Quadruped } \\
\text { (four points of support) }\end{array}$ & $\begin{array}{l}\text { Paravertebral, cervical, } \\
\text { dorsal and lumbar }{ }^{(27)}\end{array}$ & Elbow and hip extensors ${ }^{(25)}$ \\
\hline Squatting & & Pelvic floor ${ }^{(25)}$ \\
\hline
\end{tabular}

The exercises performed in supine position lasted no more than 5 minutes, thus avoiding reduction in venous return ${ }^{(21,28)}$.

The physical activity applied was of medium intensity, using as reference Borg subjective scale. The pregnant women were instructed to use as limit levels 13 to 14 of the said scale or when they felt slightly tired ${ }^{(13)}$, since this is the limit recommended by $\mathrm{ACOG}^{(12,21)}$. Two weeks after delivery, telephone contact was made with all participants to collect information as to the mode of delivery. The participant was also questioned as to whether she participated in any physical activity besides that offered by the study, in the case of the EG, or if she engaged in any type of regular physical activity, in the case of the CG.

The data from this study were analyzed adopting a $5 \%$ significance level $(\mathrm{p}=0.05)$. The values calculated for probability of error (p), when $<0.05$, were considered statistically significant, and were marked with an asterisk $(*)$; when $>0.05$, they were considered non-significant.

The project was approved by the Research Ethics Committee of the Universidade Católica de São Paulo (PUC-SP), under No. 019/2008 (CEP of CIAMA - São Sebastião). 


\section{Statistical methods}

The statistical method of the chi-square test $\left(\chi^{2}\right)$ corrected for continuity was used, as per Yates, as well as the common $\chi^{2}$.

\section{RESULTS}

\section{Mode of delivery versus EG and CG}

The correlations between the two types of delivery, vaginal and cesarean, in both groups - EG and CG, were analyzed. As can be seen on table 1, the statistical analysis showed predominance of vaginal deliveries in the EG. On the other hand, in the CG, there was a predominance of cesarean sections. The corrected $\chi^{2}$ test as per Yates revealed a statistically significant difference of these proportions $\left[\chi^{2} \mathrm{c}\right.$ (Yates $\left.)=4.63 \mathrm{p}=0.031 *\right]$.

Table 1. Type of delivery versus Exercise Group and Control Group

\begin{tabular}{lccc}
\hline Type of delivery & \multicolumn{1}{c}{ EG } & CG & Total \\
& $\mathbf{n ~ ( \% )}$ & $\mathbf{n}(\%)$ & $\mathbf{n}$ \\
\hline Vaginal & $25(67.6)$ & $11(37.9)$ & 36 \\
Cesarean section & $12(32.4)$ & $18(62.1)$ & 66 \\
\hline Total & $37(100)$ & $29(100)$ & $66(100)$ \\
\hline GE: Exercise Group;GC: Control Group. & & \\
Two x two contingency table with the number of pregnant women and respective percentages as to type of deliveryin \\
groups EG and CG. \\
$\chi^{2}$ calculation corrected for continuity, as per Yates. \\
$\chi^{2} \mathrm{C}$ (Yates)=4.64; $p=0.031^{*}$.
\end{tabular}

\section{Level of schooling versus EG and CG}

Correlations between the levels of schooling (first, second, third) of the women in groups EG and $\mathrm{CG}$ were evaluated. A predominance of the second level of schooling was noted, both for EG and for CG, both of them with 39 women each, with a total of $66(59.1 \%)$. On the other hand, there was opposition between the first and third levels: in the EG, there was predominance of the third level relative to control, and in the CG the first level predominated relative to the EG. The simple $\chi^{2}$ test showed a statistical difference between these two groups $\left(\chi^{2}=3.33 ; p=0.01736^{*}\right)$, as illustrated on table 2 .

Table 2. Level of schooling versus Exercise Group and Control Group

\begin{tabular}{lccc}
\hline Schooling & $\begin{array}{c}\text { EG } \\
\mathbf{n}(\%)\end{array}$ & $\begin{array}{c}\text { CG } \\
\mathbf{n}(\%)\end{array}$ & $\begin{array}{c}\text { Total } \\
\mathbf{n}\end{array}$ \\
\hline First level & $6(16.2)$ & $9(31.0)$ & 15 \\
Second level & $20(23.5)$ & $26(53.1)$ & 39 \\
Third level & $11(29.7)$ & $1(3.5)$ & 12 \\
\hline Total & $37(100)$ & $29(100)$ & 66 \\
\hline
\end{tabular}

GE: Exercise Group; GC: Control Group.

Three $\mathrm{x}$ two contingency table with the number of pregnant women and respective percentages as to their level of schooling, in groups $E G$ and $C G$

$\chi^{2}$ calculation with its respective significance level.

$\chi^{2}=3.33 ; p=0.01736^{*}$

\section{DISCUSSION}

A greater chance of having vaginal deliveries among pregnant women who engage in physical activity during gestation is one of the possible benefits of this effort $^{(9-11)}$. In the sample studied, a larger number of vaginal deliveries were noted in those who participated in the EG relative to those who remained sedentary. Bungum et al..$^{(9)}$, who studied primiparas that gave selfdescribed information about having engaged in physical activity during gestation, found no statistical difference as to type of delivery (vaginal or cesarean), between the group that had engaged in activity and the one that had remained sedentary; however, those who remained inactive during gestation had about two-fold greater chances of having a cesarean section. The difference relative to this present investigation perhaps occurred because in that study, activity was self-reported, with no precision as to the number of exercise sessions or the time spent on the activity. Cavalcante et al. ${ }^{(10)}$ accompanied pregnant women who engaged in physical activity in the water and noted that the number of vaginal deliveries was greater among the active participants than among those who did no exercise during gestation; nevertheless, no statistical difference was found. The reason for this difference might have been the fact that, in the present study, the pregnant women received classes before the exercise sessions that valued vaginal birth, and it may be that these repeated classes (although this was not the objective of this project) in some way influenced the decision as to mode of delivery, which would be a characteristic different from other works in literature. Another study that evaluated physical exercise during gestation and its influence on the type of delivery was carried out by Zeanah \& Schlosser ${ }^{(11)}$, in which the pregnant women who exercised with low and medium intensity had more vaginal deliveries. The result of that study agrees with that found in this present study. Another possibility is the fact that the exercises might strengthen the abdominal muscles, facilitating the second stage of labor and avoiding possible dystocia or excessive prolonging of labor time, conditions which, per se, would indicate the need for a cesarean section ${ }^{(28)}$.

As to schooling level of the participants, the women with the second level of education were majority, both in the EG and in the CG groups. One aspect to be considered is that both the recruitment of the pregnant women and the venue of the activity were located in a poor neighborhood of the city. However, most pregnant women with the third level of schooling were a part of the EG group, and most of the women participating who had only completed the first level of schooling were in the CG. Most of the pregnant women who only had 
the basic level of education lived in the neighborhood where the study was carried out, and none of the participants with the third level of schooling lived in this area, and thus had to travel a greater distance. Therefore, this direct relation between compliance with exercise and level of education was unusual. Domingues and Barros studied 4471 pregnant women and noted that the poorer women and those with the lowest levels of education were less likely to engage in leisure physical activities ${ }^{(29)}$. In other populations, a association was also found between the level of schooling and compliance with physical exercise, such as in the study by SallesCosta et al. ${ }^{(30)}$, who observed a direct relation between the education level and the practice of physical exercise among 4030 employees of the Universidade do Estado do Rio de Janeiro (UERJ).

There are several limitations in this study, such as the fact that the subjects were not randomized. However, in order to be included in the study, the pregnant women could not have participated in a regular exercise program during the year prior to her gestation, which would decrease the bias of the research by the fact of having worked with previously selected women. Another limiting factor was the withdrawal of participants during the physical activity program. During the study, approximately $30 \%$ of the selected pregnant women withdrew from participating in the program, thus reducing the sample. The decrease in physical activity during gestation was indicated by Liu et al. ${ }^{(31)}$ in a study with 9989 women, in which two out of every three, when initiating pregnancy, informed that they reduced their physical activity.

Nevertheless, the present study, as it focuses on this issue, hopes that new controlled randomized studies with larger samples be carried out.

\section{CONCLUSIONS}

In the population studied, the exercise program during gestation had an influence on the type of delivery, which proved positive regarding vaginal births. A greater compliance with exercising was also noted among the women with higher education levels.

\section{ACKNOWLEDGEMENTS}

To nurse Carla Silveira, in charge of Centro de Incentivo ao Aleitamento Materno (CIAMA).

\section{REFERENCES}

1. Villar J, Carroli G, Zavaleta N, Donner A, Wojdyla D, Faundes A, Velazco A, Bataglia V, Langer A, Narváez A, Valladares E, Shah A, Campodónico L,
Romero M, Reynoso S, de Pádua KS, Giordano D, Kublickas M, Acosta A World Health Organization 2005 Global Survey on Maternal and Perinatal Health Research Group. Maternal and neonatal individual risks and benefits associated with caesarean delivery: multicentre prospective study. BMJ. 2007;335(7628):1025.

2. Shearer E. Cesarean section: medical benefits and costs. Soc Sci Med. 1993; 37(10):1223-31.

3. Gerten K, Coonrod D, Bay R, Chambliss L. Cesarean delivery and respiratory distress syndrome: does labor make a difference? Am J Obstet Gynecol. 2005;193(3 pt 2):1061-4.

4. Grobman W, Peaceman A, Socol M. Cost-effectiveness of elective cesarean delivery after one prior low transverse cesarean. Obstet Gynecol. 2000; 95(5):745-51.

5. Myers S, Gleicher N. A successful program to lower cesarean-section rates. N Engl J Med. 1988;319(23):1511-16.

6. Brasil. Ministério da Saúde/SVS - Sistema de Informações sobre Nascidos Vivos (SINASC). RIPSA. IDB. F-8; 2011

7. Agência Nacional de Saúde Suplementar (ANS). 0 modelo de atenção obstétrica no setor de saúde suplementar no Brasil: Cenários e perspectivas. Rio de Janeiro; 2008.

8. Chalmers B. WHO appropriate technology for birth revisited. Br J Obstet Gynaecol. 1992;99(9):709-10.

9. Bungum T, Peaslee D, Jackson A, Perez M. Exercise during pregnancy and type of delivery in nulliparae. J Obstet Gynecol Neonatal Nurs. 2000;29(3):258-64.

10. Cavalcante S, Cecatti J, Pereira R, Baciuk E, Bernardo A, Silveira C. Water aerobics II: maternal body composition and perinatal outcomes after a program for low risk pregnant women. Reprod Health. 2009;6(1):1-7.

11. Zeanah M, Schlosser S. Adherence to ACOG guidelines on exercise during pregnancy: effect on pregnancy outcome. J Obstet Gynecol Neonatal Nurs. 1993;22(4):329-35

12. ACOG Committee opinion. Number 267, January 2002: exercise during pregnancy and the postpartum period. Obstet Gynecol. 2002;99(1):171-3.

13. Artal R, O'Toole M, White S. Guidelines of the American College of Obstetricians and Gynecologists for exercise during pregnancy and the postpartum period. Br J Sports Med. 2003;37(1):6-12, discussion 12.

14. Juhl $M$, Andersen PK, Olsen J, Madsen M, Jørgensen T, Nøhr EA, et al. Physical exercise during pregnancy and the risk of preterm birth: $A$ study within the Danish national birth cohort. Am J Epidemiol. 2008;167(7):859-66.

15. San Juan Dertkigil M, Cecatti J, Sarno M, Cavalcante S, Marussi E. Variation in the amniotic fluid index following moderate physical activity in water during pregnancy. Acta Obstet Gynecol Scand. 2007;86:(5):547-52.

16. Liu J, Laditka J, Mayer-Davis E, Pate R. Does physical activity during pregnancy reduce the risk of gestational diabetes among previously inactive women? Birth. 2008;35(3):188-95.

17. Kardel K, Kase T. Training in pregnant women: effects on fetal development and birth. Am J Obstet Gynecol. 1998;178(2):280-6.

18. Santos I, Stein R, Fuchs S, Duncan B, Ribeiro J, Kroeff L, et al. Aerobic exercise and submaximal functional capacity in overweight pregnant women. Obstet Gynecol. 2005;106(2):243-9.

19. Garshasbi A, Faghih Zadeh S. The effect of exercise on the intensity of low back pain in pregnant women. Int J Gynaecol Obstet. 2005;88(3):271-5.

20. Mørkved S, Bø K, Schei B, Salvesen. Pelvic floor muscle training during pregnancy to prevent urinary incontinence: a single-blind randomized controlled trial. Obstet Gynecol. 2003;101(2):313-9.

21. Exercise during pregnancy and the postpartum period. ACOG Technical Bulletin Number 189 - February 1994. Int J Gynaecol Obstet. 1994;45(1):65-70.

22. Watson WJ, Katz VL, Hackney AC, Gall MM, McMurray RG. Fetal responses to maximal swimming and cycling exercise during pregnancy. Obstet Gynecol. 1991;77(3):382-6.

23. Dwarkanath P, Muthayya S, Vaz M, Thomas T, Mhaskar A, Mhaskar R, et al. The relationship between maternal physical activity during pregnancy and birth weight. Asia Pac J Clin Nutr. 2007;16(4):704-10. 
24. Polden M, Mantle Jill. Fisioterapia em ginecologia e obstetrícia. 2a ed. São Paulo: Santos; 1997.

25. Zamataro, Valéria. 0 papel da fisioterapia no preparo para o parto de cócoras. Fisioter Mov. 1996;8(2):48-53.

26. Baracho E. Fisioterapia aplicicada à obstetrícia, uroginecologia e mastologia. 4a ed. Rio de Janeiro: Medsi; 2007.

27. Kisner $C$, Colby LA. Exercícios terapêuticos: fundamentos e técnicas. 2a ed. São Paulo: Manole; 1992.

28. Bovbjerg ML, Siega-Riz AM. Exercise during pregnancy and cesarean delivery: North Carolina PRAMS, 2004-2005. Birth. 2009;36(3):200-7.
29. Domingues MR, Barros AJ. Leisure-time physical activity during pregnancy in the 2004 Pelotas Birth Cohort Study. Rev Saude Publica. 2007;41(2): $173-80$.

30. Salles-Costa R, Werneck GL, Lopes CS, Faerstein E. [The association between socio-demographic factors and leisure-time physical activity in the Pró-Saúde Study]. Cad Saude Publica. 2003;19(4):1095-105. Article in Portuguese.

31. Liu J, Blair SN, Teng Y, Ness AR, Lawlor DA, Riddoch C. Physical activity during pregnancy in a prospective cohort of British women: results from the Avon longitudinal study of parents and children. Eur J Epidemiol. 2011;26(3): 237-47. 